\title{
Las enfermedades periodontales como infecciones bacterianas
}

\author{
BASCONES MARTINEZ A* \\ FIGUERO RUIZ E**
}

\begin{abstract}
Bascones Martínez A, Figuero Ruiz E. Las enfermedades periodontales como infecciones bacterianas. Av Periodon Implantol. 2005; 17, 3: 147-156.
\end{abstract}

\begin{abstract}
RESUMEN
Las infecciones periodontales son un conjunto de enfermedades localizadas en las encías y estructuras de soporte del diente. Están producidas por ciertas bacterias provenientes de la placa bacteriana. Estas bacterias son esenciales para el inicio de la enfermedad, pero existen factores predisponentes del hospedador y microbianos que influyen en la patogénesis de la enfermedad. La microbiota bacteriana periodontopatógena es necesaria pero no suficiente para que exista enfermedad, siendo necesaria la presencia de un hospedador susceptible. Estas enfermedades se han clasificado en gingivitis, limitadas a las encías y periodontitis, extendidas a tejidos más profundos. La clasificación de las enfermedades periodontales ha ido variando a lo largo de los años y es en el International Workshop for a Clasification of Periodontal Diseases and Conditions, en 1999, cuando se aprueba la clasificación que se expone en este trabajo. En él, se hace una revisión global de los diferentes cuadros de las enfermedades periodontales. Posteriormente, se propone el empleo de antibioterapia de utilización sistémica como la amoxicilina, amoxicilina-clavulánico y metronidazol como primera opción de tratamiento coadyuvante de estas enfermedades.
\end{abstract}

\section{PALABRAS CLAVE}

Clasificación, enfermedades periodontales, biofilm

Publicado en Med Oral Patol Oral Cir Bucal 2004; 9 Suppl:S92-107

Aceptado para publicación: Abril 2005

\section{INTRODUCCIÓN}

El término infección se emplea para referirse a la presencia y multiplicación de microorganismos en el cuerpo (1). Las infecciones periodontales son un conjunto de enfermedades que, localizadas en la encía y las estructuras de soporte del diente (ligamento y hueso alveolar), están producidas por ciertas bacterias prove- nientes de la placa subgingival (Fig.1). Las bacterias anaerobias gramnegativas más importantes y prevalentes en el área subgingival son el Actinobacillus actinomycetemcomitans (Aa), Porphyro-monas gingivalis $(\mathrm{Pg})$, Prevotella intermedia (Pi) y Tannerella forsythensis (Tf). Estas bacterias tienen un importante papel en el comienzo y posterior desarrollo de la periodontitis participando en la formación de la bolsa periodontal, destrucción del tejido conectivo y reabsorción del

* Catedrático de Medicina Bucal y Periodoncia. Departamento de Estomatología III. Facultad de Odontología. Universidad Complutense de Madrid.

** Licenciada en Odontología. Becaria del Programa Nacional de Formación de Profesorado Universitario del Ministerio de Educación, Cultura y Deporte. Alumna de doctorado. 


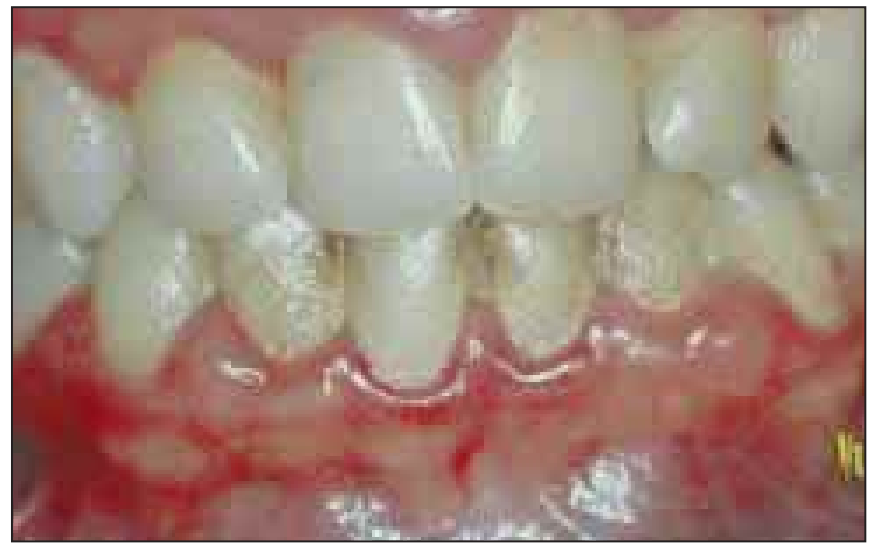

Fig. 1. Inflamación gingival intensa con abundantes depósitos bacterianos.

Intense gingival inflammation with abundant bacterial deposits.

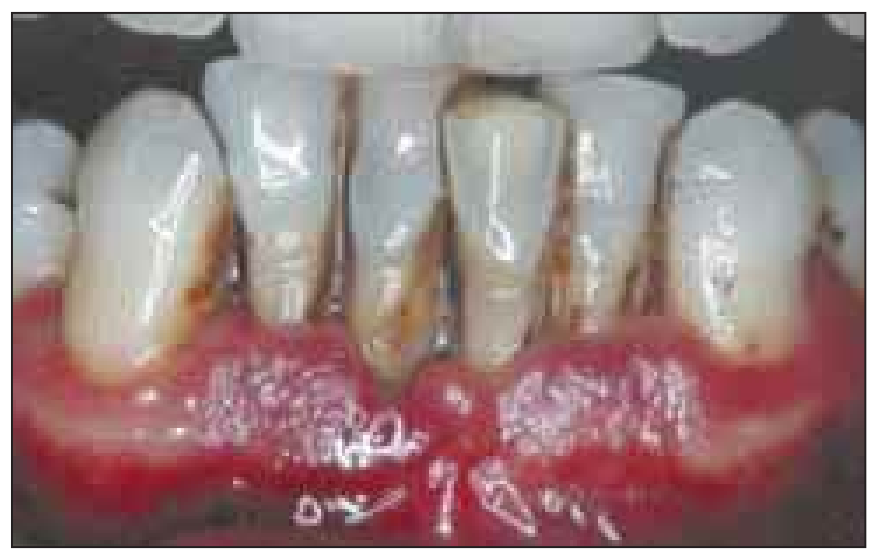

Fig. 2. Periodontitis crónica.

Chronic periodontitis.

\section{TABLA 1.- INFECCIONES}

Polimicrobianas (3-6 especies)

Mixtas (aerobios, facultativos, anaerobios)

Inespecíficas Igual clínica diferente etiología

Oportunistas Flora de la placa dental

hueso alveolar a través de un mecanismo inmunopatogénico. Una vez establecida la periodontitis, se forma un infiltrado inflamatorio constituido por diferentes tipos celulares como macrófagos y linfocitos, que producirán distintos subtipos de citoquinas, mediadores biológicos responsables de la inmunopatología de diversas enfermedades (Tabla l) (Fig.2).

La mayor parte de los microorganismos encontrados en la naturaleza crecen sobre las superficies en forma de biofilm, siendo la placa dental un claro ejemplo del mismo. Actualmente se sabe que el fenotipo que expresan las bacterias al crecer sobre una superficie es diferente a cuando lo hacen de forma planctónica. Esto va a tener una importante relevancia clínica, especialmente debido al incremento en la resistencia de los biofilms a los agentes antimicrobianos $(2,3)$. La formación de un biofilm pasa por una serie de fases, que comienzan con la adsorción de moléculas del huésped y bacterianas a la superficie del diente para formar la llamada película adquirida, que permite que los microorganismos transportados de forma pasiva hasta ella interaccionen mediante fuerzas de atracción de Van der Waals y fuerzas de repulsión y atracción electrostáticas, para crear una unión débil. Posteriormente esta unión se refuerza mediante la aparición de fuertes interacciones mediadas por moléculas específicas en la superficie de las bacterias (adhesinas) con los receptores complementarios de las mismas en la película dental. Con el paso del tiempo, los fenómenos de coagregación de nuevos colonizadores y los de multiplicación permitirán la adhesión firme de las bacterias a la superficie dental $(2,3)$. La expresión clínica de los diferentes cuadros de periodontitis dependerá de la interacción entre factores del hospedador, ambientales y del agente microbiológico. Un ambiente favorable y factores genéticos positivos determinan la diferente susceptibilidad del individuo, y no sólo eso, sino también la distinta severidad de los cuadros clínicos, la tasa de progresión, la recidiva y la aleatoria respuesta a la terapéutica. Por lo tanto, la microbiota bacteriana periodontopatógena es necesaria pero no suficiente para que exista enfermedad, siendo necesaria la presencia de un hospedador susceptible (4). Hay estudios epidemiológicos que han demostrado una asociación significativa entre la gravedad de las enfermedades periodontales, la cantidad de placa dental y el grado de higiene bucal, existiendo una relación causa-efecto entre la formación y el acúmulo de placa dental y el desarrollo de la gingivitis. En este sentido son importantes los estudios de Löe (5) (1965), en Dinamarca sobre la gingivitis experimental en los que demostró una asociación significativa entre acúmulo de placa bacteriana y gingivitis en los 21 días que duró el experimento. El cuadro clínico de la gingivitis desapareció al reiniciar los métodos de higiene bucal y control de placa. Posteriormente, Lindhe (6) (1973) demostró en perros beagle, con otro estudio longitudinal la periodontitis experimental. En estado de buena salud hay un equilibrio entre la agresión de bacterias y la resistencia del hospedador. Al romperse este equilibrio, bien sea por un aumento del número $\mathrm{y} / \mathrm{o}$ virulencia de los gérmenes o bien por una disminución de las defensas, surge la enfermedad. Por ello, las enfermedades se han clasificado en gingivitis, limitadas a la encía y periodontitis, extendidas a tejidos más profundos, destruyendo la inserción de tejido conectivo al cemento, formando bolsas, reabsorbiendo el hueso alveolar, movilizando el diente y finalizando con su caída. Al actuar sobre el tejido conectivo, las bacterias provocan una serie de reacciones inflamatorias e inmunológicas en el hospedador que se traducen en un acúmulo de células asociadas a la activación de procesos de destrucción periodontal. Los estudios 


TABIA 2.- CARACTERÍSTICAS DE LA
FLORA ORAL
FLORA MUY COMPLEJA
-Heterogénea
-Múltiples especies 300 especies
-Diferentes ecosistemas
-Cuantiosa
- Específica
-Dinámica
OPORTUNISTA

longitudinales sugieren un curso episódico en la progresión de la enfermedad caracterizado por fases de quietud y exacerbación, estando representadas las primeras por un reposo y las segundas por signos de destrucción tisular. Estos episodios de destrucción periodontal están asociados a distintos cambios en la población celular que confirma el infiltrado inflamatorio localizado en el tejido conectivo subepitelial (neutrófilos, macrófagos, linfocitos, células plasmáticas, etc.) (7). A partir de la década de los 90 se ha postulado que en la patogénesis de las enfermedades periodontales ocupan un especial protagonismo, por un lado, los factores predisponentes del hospedador (como la falta de higiene oral, edad, factores sistémicos como el tabaco, diabetes, predisposición genética, alteración de las defensas, etc.) y por otro lado, los factores microbianos que influyen en la periodontopatogenicidad de los gérmenes (como son los factores específicos de adherencia bacteriana). En el momento del nacimiento, la cavidad oral es estéril, aunque rápidamente se inicia la colonización bacteriana, constituyéndose la llamada flora microbiana oral o microbiota, donde cohabitan aerobios, anaerobios estrictos (65\%), especies saprófitas y patógenas. El equilibrio (eubiosis) puede alterarse por factores exógenos 0 endógenos con lo que se presenta la enfermedad (disbiosis). La placa bacteriana localizada en el margen gingival (supra y subgingival) es la iniciadora de la enfermedad, en mayor medida por supuesto la subgingival que tiene un mayor contacto con los tejidos de soporte del diente. Esta última placa está formada por bacterias anaerobias, gram negativas, formas móviles y espiroquetas, localizadas en un área donde se dan condiciones muy favorables (bolsa, anaerobiosis, PH, potencial óxido-reducción, menor autoclisis, etc). Así pues, la microbiota es polimicrobiana y mixta siendo las enfermedades muchas veces consecuencia de asociaciones bacterianas complejas (Tabla 2).

\section{CLASIFICACION DE LAS ENFERIMEDADES PERIODONTALES}

Durante muchos años, la Asociación Americana de Periodoncia ha clasificado las enfermedades perio-

\section{TABLA 3.- CLASIFICACIÓN DEL WORD WORISHOP, 1989}

A. GINGIVITIS

a. Asociada a placa.

b. Gingivitis ulcerativa necrotizante aguda (GUNA).

c. Gingivitis inducida por hormonas esteroideas.

d. Agrandamientos gingivales inducidos por medicamentos.

e. Gingivitis asociada a desórdenes sanguíneos, deficiencias nutricionales, tumores, factores genéticos, infecciones víricas.

f. Gingivitis descamativa.

B. PERIODONTITIS

a. Periodontitis del adulto.

b. Periodontitis de comienzo temprano:

i. Periodontitis prepuberal:

1.1. Localizada

2.2. Generalizada

ii. Periodontitis juvenil

1.1. Localizada

2.2. Generalizada

c. Periodontitis asociada a enfermedades sistémicas

d. Periodontitis ulcerativa necrotizante

e. Periodontitis refractaria

\section{TABLA 4.- CLASSIFICACIÓN EUROPEAN WORISHOP, 1993}
A. DESCRIPTORES PRIMARIOS
a. Periodontitis del adulto.
b. Periodontitis de aparición temprana.
c. Periodontitis necrotizante.

\section{B. DESCRIPTORES SECUNDARIOS}
a. Distribución de la dentición.
b. Ritmo de progresión.
c. Respuesta al tratamiento.
d. Relación con enfermedades sistémicas.
e. Características microbiológicas.
f. Grupo étnico.
g. Otros factores.

dontales en gingivitis y periodontitis (suave, moderada, severa y refractaria), en función de la región periodontal afectada. En 1989 en el World Workshop on Clinical Periodontics se estableció una nueva clasificación caracterizada por la incorporación de nuevas entidades nosológicas (Tabla 3). Posteriormente, en el Primer Workshop Europeo de Periodoncia (1993) se propone una clasificación más simple de las enfermedades periodontales basada principalmente en los factores causales asociados a las mismas y en la diferente respuesta del hospedador (Tabla 4). Estas clasificaciones han sido ampliamente empleadas tanto por 
clínicos como por investigadores, sin embargo, presentan una serie de fallos. De este modo, en la clasificación del International Workshop, de 1989, existe un solapamiento entre las diferentes categorías, destaca la ausencia de la enfermedad gingival, se hace un énfasis inadecuado en la edad de comienzo de la enfermedad así como en las tasas de progresión y la existencia de unos criterios de clasificación inadecuados. Por otro lado, la clasificación Europea de 1993 carece de los detalles necesarios para la adecuada identificación del gran espectro de enfermedades periodontales que se encuentran en la práctica clínica. Por ello, en el World Workshop in Periodontics de 1996 se enfatiza la necesidad de revisar las clasificaciones existentes y crear una nueva. En 1997, la Asociación Americana de Periodoncia decide formar un comité encargado de esta tarea, y es en el International Workshop for a Clasification of Periodontal Diseases and Conditions (1999) cuando se aprueba la clasificación propuesta por dicho comité (Tabla 5).

\section{Enfermedades gingivales inducidas por placa}

El término "enfermedades gingivales" se emplea para definir el patrón de signos y síntomas de diferentes enfermedades localizadas en la encía. Todas ellas se caracterizan por presentar placa bacteriana que inicia o exacerba la severidad de la lesión, ser reversibles si se eliminan los factores causales y por tener un posible papel como precursor en la pérdida de inserción alrededor de los dientes. Clínicamente se aprecia una encía inflamada, con un contorno gingival alargado debido a la existencia de edema o fibrosis, una coloración roja o azulada, una temperatura sulcular elevada, sangrado al sondaje y un incremento del sangrado gingival. Todos estos signos están asociados a periodontos con niveles de inserción estables sin pérdidas de inserción, o estables aunque en periodontos reducidos (8) (Fig. 3). La gingivitis inducida por placa es una inflamación de la encía debida a la localización de bacterias en el margen

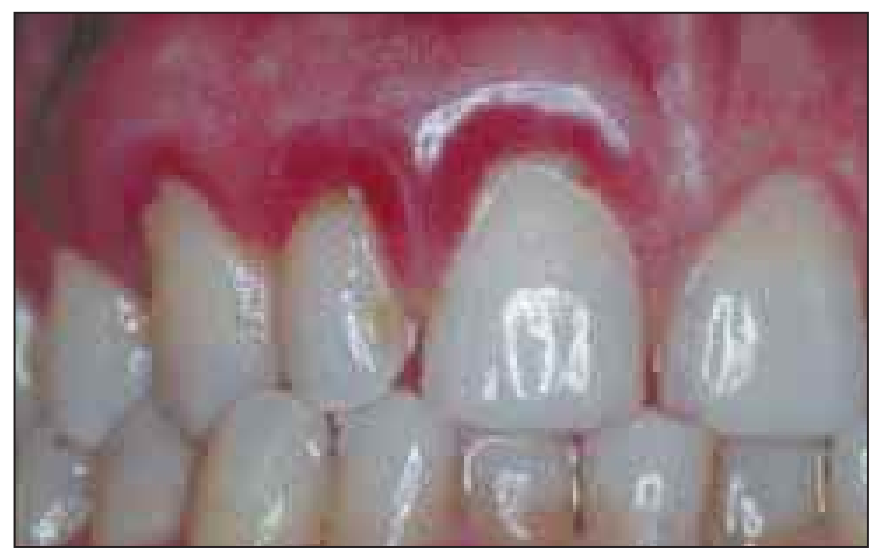

Fig. 3. Inflamación gingival en el sector anterior superior. Gingival inflammation in the anterior superior sector. gingival, y que posteriormente se puede extender a toda la unidad gingival. Los hallazgos clínicos característicos son el eritema, edema, sangrado, sensibilidad y agrandamiento. Su severidad puede verse influenciada por la anatomía dentaria así como por las situaciones restauradoras o endodónticas de cada caso (9) (Fig. 1).La gingivitis asociada a la pubertad comparte la mayor parte de los signos clínicos de la gingivitis inducida por placa pero su principal diferencia se basa en la propensión elevada a desarrollar signos francos de inflamación gingival en presencia de cantidades relativamente pequeñas de placa bacteriana durante el período circumpuberal. Durante la pubertad se produce una serie de cambios endocrinos caracterizados por la elevación de los niveles de hormonas esteroideas en sangre y que van a ser los responsables del estado de la inflamación de la encía (9). La gingivitis asociada al ciclo menstrual se caracteriza por una respuesta inflamatoria moderada de la encía previa a la fase de ovulación, con un incremento del exudado gingival en un $20 \%$, debido a la elevación de los niveles de hormonas luteinizantes ( $>25$ $\mathrm{mU} / \mathrm{ml}$ ) y/o de estradiol (>200 pg/ml) (9). La gingivitis asociada al embarazo es una inflamación proliferativa, vascular e inespecífica con un amplio infiltrado inflamatorio celular. Clínicamente se caracteriza por una encía intensamente enrojecida que sangra fácilmente, engrosamiento del margen gingival, hiperplasia de las papilas interdentales que pueden dar lugar a la aparición de pseudobolsas (10). Löe y Silness (11), en 1963, describen que los primeros síntomas aparecen en el segundo mes de embarazo y continúan hasta el octavo, momento a partir del cual se observa cierta mejoría para estabilizarse finalmente tras el parto. Los estudios clínicos muestran una prevalencia que varía entre el 35 y el 100\% (11) de las embarazadas. El granuloma gravídico, también llamado tumor del embarazo, es una reacción inflamatoria proliferativa fibrovascular exagerada en relación a un estímulo ordinario (12) localizada fundamentalmente en la encía. Se describe como una masa localizada roja o roja-amoratada, nodular o ulcerada que sangra fácilmente y que aparece frecuentemente en mujeres $(0,5-$ $5 \%)(13,14)$ en torno al segundo trimestre de embarazo y crece a lo largo del mismo alcanzando un tamaño que no suele superar los $2 \mathrm{~cm}$. Su etiología es desconocida, pero se han implicado factores traumáticos, higiénicos y hormonales (13). En la gingivitis asociada a diabetes mellitus el nivel de control diabético es más importante que el control de placa en la severidad de la inflamación gingival. Este tipo de gingivitis suele presentarse en niños con una diabetes mellitus tipo I mal controlada. La gingivitis asociada a leucemia se caracteriza por presentar unos tejidos gingivales inflamados y esponjosos con una coloración que varía entre el rojo y el morado. El sangrado gingival es frecuente y puede ser la primera manifestación de una leucemia aguda o crónica en un 17,7\% y un $4,4 \%$ de los casos, respectivamente. Los agran- 


\section{TABLA 5.- CLASIFICACIÓN DE ENFERMEDADES PERIODONTALESY CONDICIONES DEL INTERNATIONAL WORKSHOP (1999)}

\section{ENFERMEDADES GINGIVALES}

\section{PERIODONTITIS CRÓNICA}

a. Inducidas por placa: a. Localizada.

i. Gingivitis asociada sólo con placa dental. b. Generalizada.

1.1. Sin otros factores locales asociados

III. PERIODONTITIS AGRESIVA

2.2. Asociada también a otros factores locales. a. Localizada.

ii. Modificadas por factores sistémicos b. Generalizada.

1. Asociadas con el sistema endocrino

IV. PERIODONTITIS COMO MANIFESTACIÓN DE ENFERMEDADES SISTÉMICAS

a. Gingivitis asociada a la pubertad.

b. Gingivitis asociada al ciclo menstrual. a. Asociada a desórdenes hematológicos:

c. Asociadas al embarazo: i. Neutropenia adquirida.

i. Gingivitis.ii. Leucemias.

ii. Granuloma piogénico. iii. Otras.

d. Gingivitis asociada a diabetes mellitus. b. Asociada a desórdenes genéticos:

2. Asociadas con discrasias sanguíneas: i. Neutropenia familiar y cíclica.

a. Gingivitis asociada a leucemia. ii. Síndrome de Down.

b. Otras. iii. Síndrome de déficit de adhesión leucocitaria.

iii.Modificadas por medicamentos iv. Síndrome de Papillon-Lefèvre.

1.1. Agrandamientos gingivales. v. Síndrome de Chediak-Higashi.

2. Gingivitis asociada a medicamentos: vi. Síndrome de histiocitosis.

a. Asociada a anticonceptivos orales. vii. Enfermedad de almacenamiento del glucógeno.

b. Otras. viii. Agranulocitosis infantil genética.

iv. Modificadas por malnutrición: ix. Síndrome de Cohen.

1.1. Déficit de ácido ascórbico. x. Síndrome de Ehler-Danlos (tipos IV y VII).

2.2. Otras. xi. Hipofosfatasia.

b. No asociadas a placa bacteriana: xii. Otros.

i. De origen bacteriano específico: c. No especificados.

1.1. Lesiones asociadas a Neisseria gonorrhoeae.

V. ENFERMEDADES PERIODONTALES NECROTIZANTES

2.2. Lesiones asociadas a Treponema pallidum. a. Gingivitis ulcerativa necrotizante (GUN).

3.3. Lesiones asociadas a especies de Streptococcus. b. Periodontitis ulcerativa necrotizante (PUN).

4.4. Otras.

ii. De origen viral

VI. ABSCESOS DEL PERIODONTO

1. Infecciones por herpes virus: a. Absceso gingival.

a. Gingivoestomatitis herpética primaria. b. Absceso periodontal.

b. Herpes oral recidivante. c. Absceso pericoronal.

c. Infecciones por varicela-zoster. 2. Otras.

VII. PERIODONTITIS ASOCIADA A LESIONES ENDODÓNTICAS

iii.De origen fúngico: a. Lesiones combinadas perio-endo.

1. Infecciones por Candida

VIII. CONDICIONES Y DEFORMIDADES ADOUIRIDAS O DEL DESARROLLO

a. Candidosis gingival generalizada.

1.2. Eritema gingival lineal. a. Factores localizados relacionados con el diente que modifican

2.3. Histoplasmosis. o predisponen a la presencia de enfermedades gingivales/

3.4. Otras. periodontales inducidas por placa:

iv. De origen genético: i. Factores anatómicos del diente.

1.l. Fibromatosis gingival hereditaria. ii. Aparatos y restauraciones dentales.

2.2. Otras. iii. Fracturas radiculares.

v. Manifestaciones gingivales de condiciones sistémicas: iv. Reabsorción radicular cervical y lágrimas del

1. Desórdenes mucocutáneos: cemento.

a. Liquen plano. b. Deformaciones y condiciones mucogingivales alrededor de

b. Penfigoide. los dientes:

c. Pénfigo vulgar. i. Retracción gingival:

d. Eritema multiforme. 1. Superficies vestibulares o linguales.

e. Lupus eritematoso. 2. Interproximal (papila).

f. Inducidos por medicamentos. ii. Ausencia de encía queratinizada.

g. Otros. iii. Profundidad del vestíbulo disminuida.

2. Reacciones alérgicas: iv. Frenillo aberrante/posición muscular.

a. Materiales dentales: v. Exceso gingival:

i. Mercurio. 1. Pseudobolsa.

ii. Níquel.2. Margen gingival inconsistente.

iii.Acrílico.3. Apariencia gingival excesiva.

iv. Otros.4. Agrandamiento gingival.

b. Atribuibles a: vi. Color anormal.

i. Pastas dentífricas. c. Condiciones y deformidades mucogingivales en crestas

ii. Colutorios.desdentadas:

iii.Aditivos de chicles. i. Cresta vertical y/u horizontal deficiente.

iv. Aditivos y comidas. ii. Falta de encía o tejido queratinizado.

c. Otros. iii. Agrandamiento gingival o de tejido blando.

vi. Lesiones traumáticas (facticias, yatrógenas, accidentales) iv. Frenillo aberrante/posición muscular.

1.1. Lesión química. v. Profundidad del vestíbulo disminuida.

2.2. Lesión física. vi. Color anormal.

3.3. Lesión térmica. d. Trauma oclusal:

vii. Reacciones de cuerpo extraño. i. Trauma oclusal primario.

viii. Otras no especificadas.

ii.Trauma oclusal secundario. 

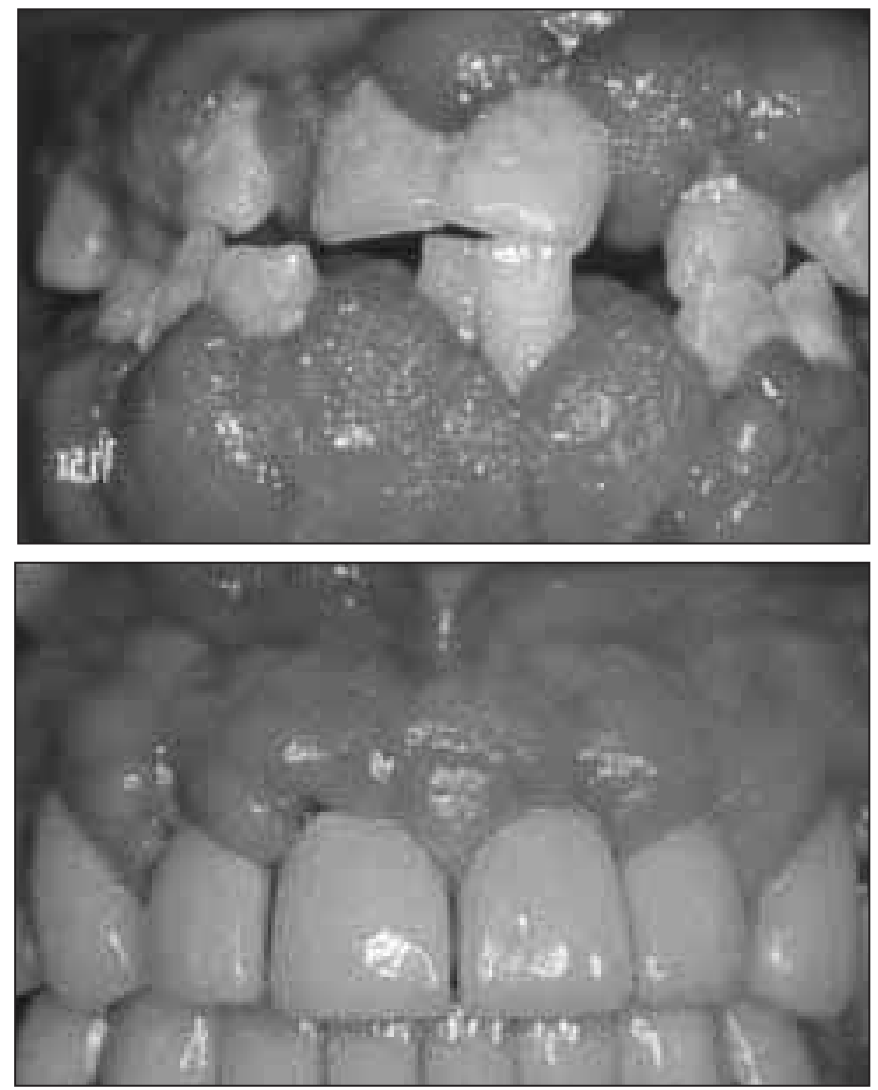

Fig. 4.1 y 4.2. Inflamación gingival por hidantoinas. Gingival inflammation by hydantoin-induced.

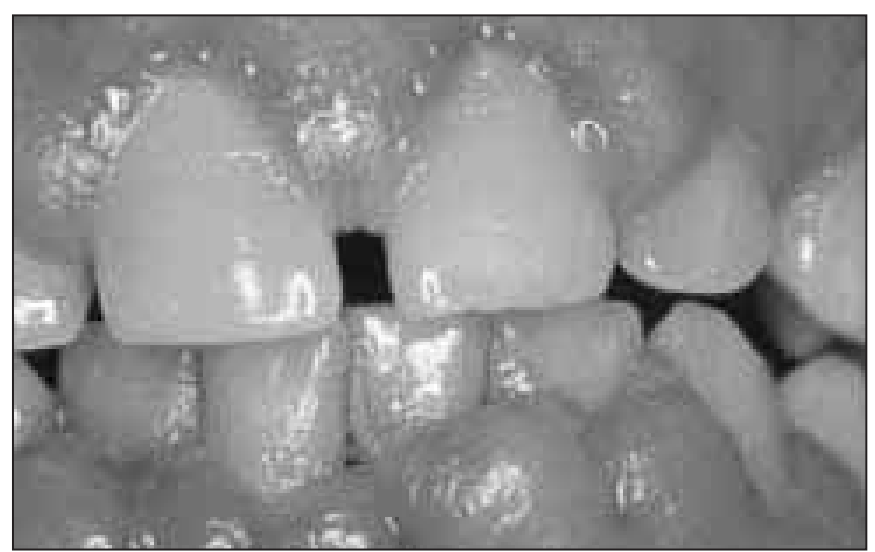

Fig. 5. Inflamación gingival por hidantoinas. Gingival inflammation hydantoin-induced.

damientos gingivales están asociados a la ingesta de anticonvulsivantes (fenitoína), inmunosupresores (ciclosporina A) y bloqueantes de los canales del calcio (nifedipino, verapamilo, diltiazem, valproato sódico). Existen variaciones inter e intrapacientes, aunque se suelen producir en la porción anterior de la encía, con mayor prevalencia en pacientes jóvenes. Suele aparecer a los tres meses de uso del fármaco, normalmente a nivel de la papila y no se asocia a pérdida de inserción (Figs.4-7). Se han observado otros casos de

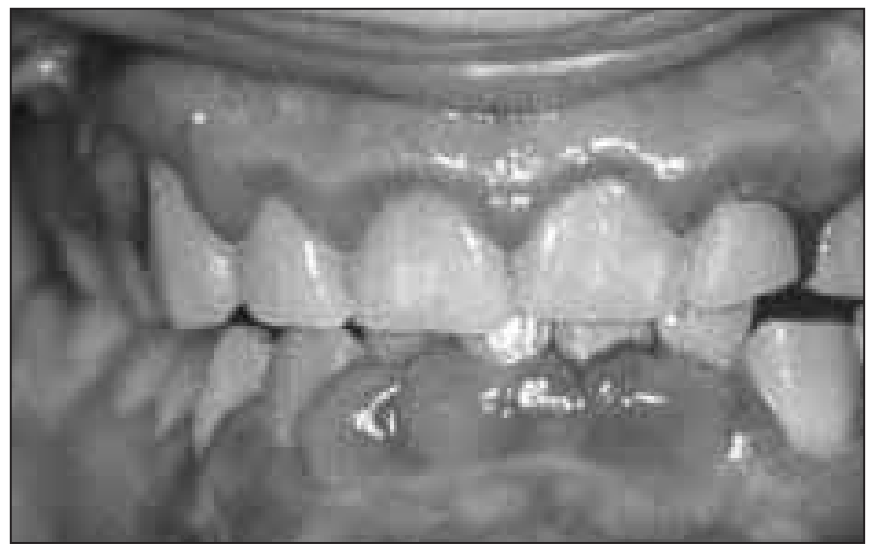

Fig. 6. Hipertrofia gingival por hidantoinas con inflamación. Hydantoin-induced gingival hypertrophy with are inflammatory accumulation.

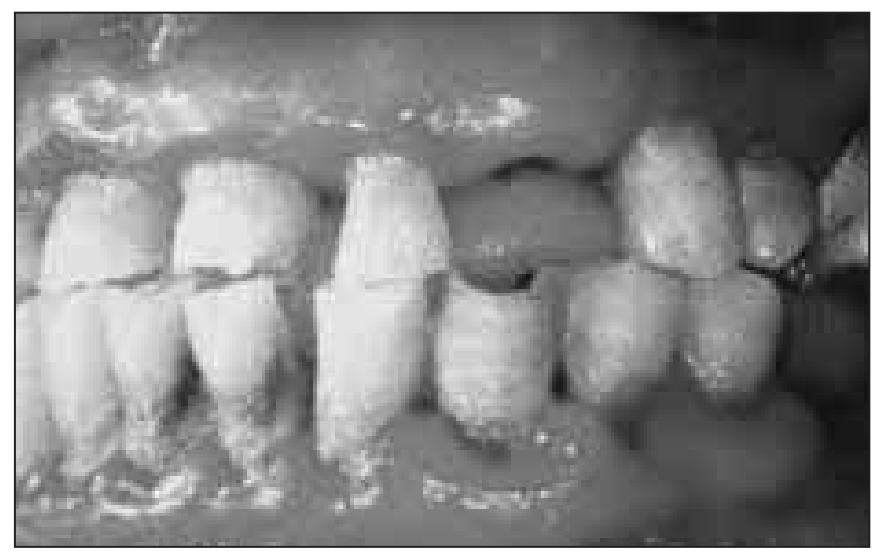

Fig. 7. Hipertrofia gingival nifedipino.

Nifedipin-induced gingival hypertrophy.

agrandamientos gingivales asociados a la ingesta de anticonceptivos orales, donde aparece una mayor inflamación del tejido gingival con presencia de cantidades relativamente pequeñas de placa. Los sujetos malnutridos presentan un compromiso en su sistema inmune, lo que puede afectar a la susceptibilidad individual a la infección, exacerbando la respuesta gingival a la presencia de placa bacteriana. La deficiencia nutricional más estudiada ha sido la de vitamina C, o escorbuto, en la cual la encía aparece de color rojo brillante, inflamada, ulcerada y con tendencia a la hemorragia.

\section{Enfermedades gingivales no inducidas por placa (15).}

\section{Las enfermedades gingivales de origen bacteria-} no son aquéllas que están inducidas por infecciones bacterianas exógenas diferentes de las que forman parte de la placa dental, tales como Neisseria gonorrhoeae, Treponema pallidum, Streptococcus y otros microorganismos. Clínicamente se manifiestan como ulceraciones edematosas dolorosas, máculas mucosas - encías muy inflamadas no ulceradas atípicas, que 
pueden estar acompañadas o no de lesiones en otras partes del cuerpo. Las enfermedades gingivales de origen viral son manifestaciones agudas de infecciones virales en la mucosa oral que cursan con la aparición de múltiples vesículas que se rompen fácilmente dando lugar a la aparición de úlceras dolorosas. Las más importantes son las asociadas a los virus del herpes simple (VHS) tipo 1 y 2 y al virus varicela-zoster. La primera manifestación del VHS-l se conoce con el nombre de gingivoestomatitis primaria. Suele aparecer en niños y cursa con una gingivitis severa y dolorosa junto con la formación de vesículas que se transforman en úlceras recubiertas por una capa de fibrina. Se puede acompañar de fiebre y linfadenopatías. La reactivación del virus se produce en un $20-40 \%$ de los casos asociada a episodios de fiebre, trauma o radiación ultravioleta, entre otros. Aparecen pequeñas úlceras dolorosas agrupadas en racimos en la zona de la encía adherida. En cuanto a la varicela, se caracteriza por la aparición de pequeñas úlceras en la lengua, paladar y encía, además de fiebre, malestar y rash cutáneo. La posterior reactivación del virus varicela-zoster da como resultado la aparición de un herpes zoster, con vesículas-úlceras irregulares y unilaterales. Las enfermedades gingivales de origen fúngico incluyen aspergilosis, blastomicosis, candidosis, coccidioidomicosis, criptococcosis, histoplasmosis, mucormicosis y paracoccidioidomicosis, siendo las más frecuentes la candidosis y la histoplasmosis. La primera, producida sobre todo por Candida albicans, raramente se manifiesta en la encía de sujetos sanos, aunque en sujetos

lineal. Otras formas de presentación son la candidosis pseudomembranosa, eritematosa, en placas o nodular. La histoplasmosis es una enfermedad granulomatosa causada por el Histoplasma capsulatum que se puede encontrar en las heces de los pájaros y los murciélagos. Se inician como lesiones nodulares que después se transforman en ulcerativas y dolorosas y que pueden tener una apariencia como la de un tumor maligno.

\section{Las manifestaciones gingivales de desórdenes mucocutáneos}

se pueden presentar como erosiones, vesículas, ampollas, úlceras o lesiones descamativas. El liquen plano se presenta entre un 0,1 y un $4 \%$ de la población de dos formas básicas: liquen plano blanco y liquen plano rojo. Se caracteriza por la existen que reciben el nombre de estrías de Wickham. El penfigoide es un grupo de desórdenes en los cuales se producen autoanticuerpos contra los componentes de la membrana basal, dando lugar a la aparición de ampollas subepiteliales, de contenido claro-amarillento o hemorrágico que se rompen dando lugar a úlceras dolorosas recubiertas por fibrina. En el pénfigo, los autoanticuerpos se dirigen contra los desmosomas del epitelio apareciendo una ampolla acantolítica o intraepitelial, que puede llegar a comprometer la vida del sujeto. El eritema multiforme es una enfermedad vesículo-ampollosa que afecta tanto a piel como a mucosas. Posee dos formas de aparición: menor y mayor (síndrome de Stevens-Johnson). Los pacientes presentan los labios inflamados con amplias costras en la zona del bermellón, aunque la lesión básica es la ampolla que se rompe apareciendo extensas úlceras. El lupus eritematoso es una enfermedad autoinmune del tejido conectivo donde los autoanticuerpos se dirigen contra diferentes elementos celulares ejerciendo su efecto en los riñones, corazón, sistema nervioso central, sistema vascular y médula ósea. La lesión típica presenta una zona central atrófica con punteado blanquecino rodeada por una fina estriación. Se clasifica en lupus eritematoso discoide y sistémico. Las reacciones alérgicas no son muy comunes en la mucosa oral debido a que se necesitan concentraciones de alergenos mayores que en la piel para que se produzcan. Pueden ser reacciones tipo I (inmediatas) mediadas por la inmunoglobulina $\mathrm{E}$

a. o tipo IV (retardada) mediada por células T. Las lesiones traumáticas en la mucosa oral se pueden producir de forma accidental, yatrogénica o facticia. Pueden presentarse en forma de recesiones gingivales localizadas, abrasiones, ulceraciones o quemaduras. Pueden tener una apariencia edematosa, eritematosa o blanquecina, o una combinación de las anteriores. Las reacciones a cuerpo extraño aparecen debido a la existencia de una ulceración epitelial que permite la entrada de una material extraño en el tejido conectivo gingival. A veces pueden presentar una inflamación gingival aguda o crónica asociada

b. o pueden producir tatuajes. En algunos casos puede aparecer supuración.

\section{Periodontitis crónica}

Los signos clínicos característicos de la periodontitis incluyen pérdida de inserción clínica, pérdida de hueso alveolar, formación de bolsas periodontales e inflamación gingival. A esto se puede asociar un sobrecrecimiento o recesión gingival, sangrado al sondaje, movilidad dentaria aumentada, supuración, pudiendo llegar a la pérdida dentaria. En los casos de periodontitis crónica la infección progresa de forma continua o en picos de actividad (16). Según su extensión puede clasificarse en:

- Localizada, si están afectadas menos de un 30\% de las localizaciones.

- Generalizada, si más del 30\% de las localizaciones 


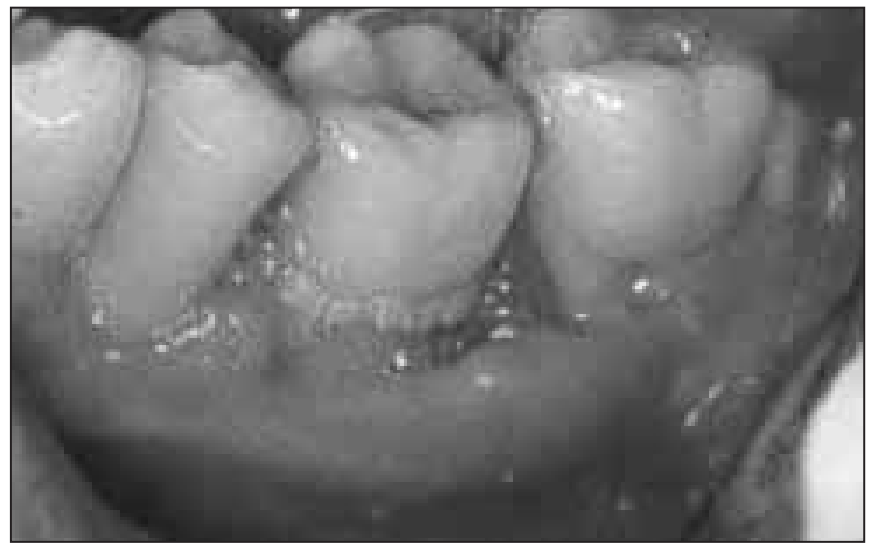

Fig. 8. Periodontitis crónica con pérdida de inserción y dientes. Chronic periodontitis with attachment and dental loss.

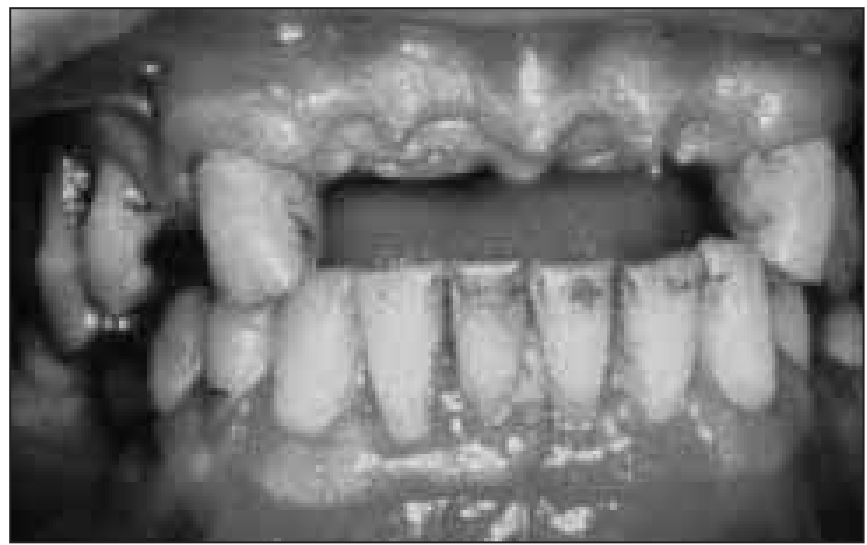

Fig. 9. Periodontitis crónica con pérdida de inserción y dientes. Chronic periodontitis with attachment and dental loss.

estánafectadas. Según su severidad se define:

- Periodontitis suave: cuando las pérdidas de inserción clínica son de 1 a $2 \mathrm{~mm}$.

- Periodontitis moderada: si las pérdidas de inserción se encuen-tran entre 3 y $4 \mathrm{~mm}$.

- Periodontitis severa: ante pérdidas de inserción clínica mayores o iguales a $5 \mathrm{~mm}$.

Los conceptos actuales demuestran que la infección bacteriana es la primera causa de la enfermedad, siendo la placa el factor iniciador de la misma, sin embargo, los mecanismos de defensa juegan un papel fundamental en su patogénesis (Figs. 8 y 9).

\section{Periodontitis agresiva}

Los rasgos comunes de las formas de periodontitis agresiva son: pacientes que salvo por la presencia de la infección periodontal son clínicamente sanos, rápida pérdida de inserción y destrucción ósea y antecedentes familiares (17). Otros rasgos que también se presentan de forma general pero no universal son: cantidad de depósitos microbianos inconsistentes con la severidad de destrucción tisular presente, proporciones elevadas de Actinobacillus actinomycetemcomitans o Porphyromonas gingivalis; anomalías en los fagocitos; fenotipo de macrófagos con hiper-respuesta con niveles elevados de prostaglandina $\mathrm{E}_{2}$ e interleuquina-1ß; la progresión de pérdida ósea y de inserción puede ser llamativa (18). Existen dos formas de periodontitis agresivas:

a. Localizada. De inicio circumpuberal y con una respuesta elevada de anticuerpos frente a los agentes infecciosos. Clínicamente se caracterizan por pérdidas de inserción interproximal en primeros molares e incisivos 0 al menos en dos dientes permanentes, uno de los cuales es un primer molar y no incluye más de dos dientes que no sean primeros molares e incisivos.

b. Generalizada. Se suele presentar en pacientes menores de 30 años, pero puede aparecer en edades superiores. La respuesta de anticuerpos es pobre. Existen episodios de pérdida de inserción, que afecta a tres dientes permanentes diferentes de primeros molares e incisivos.

\section{Enfermedades periodontales necrotizantes}

La gingivitis ulcerativa necrotizante (GUN) se diferencia del resto de enfermedades gingivales por presentar necrosis interdental gingival, con papilas ulceradas, sangrado gingival y dolor. Este dolor es la principal característica de esta entidad y su elevada intensidad lleva al paciente a buscar tratamiento. Otros signos y síntomas también asociados a la GUN, aunque no patognomónicos, son la presencia de linfadenopatías, fiebre, halitosis y malestar general (Fig. 10) Los episodios se resuelven en unos días tras recibir el tratamiento adecuado. Existen una serie de factores que predisponen la aparición de esta infección tales como el estrés, la inmunosupresión, la malnutrición, el tabaco, traumatismo, o la existencia de una gingivitis previa (19). La periodontitis ulcerativa necrotizante (PUN) es una infección caracterizada por una necrosis del tejido gingival, del ligamento periodontal y del hueso alveolar. Suele presentarse en sujetos con condiciones sistémicas que conduzcan a un estado de inmunosupresión (20). Puede ser que la GUN y la PUN sean dos estados diferentes de la misma infección y aún no existen suficientes datos para separar ambas entidades en dos categorías diferentes. La única diferencia entre ambas se basa en que la GUN se limita a la encía, mientras que la PUN incluye todo el aparato de inserción.

\section{Abscesos periodontales}

Un absceso periodontal es una infección purulenta localizada en los tejidos periodontales que puede ser 


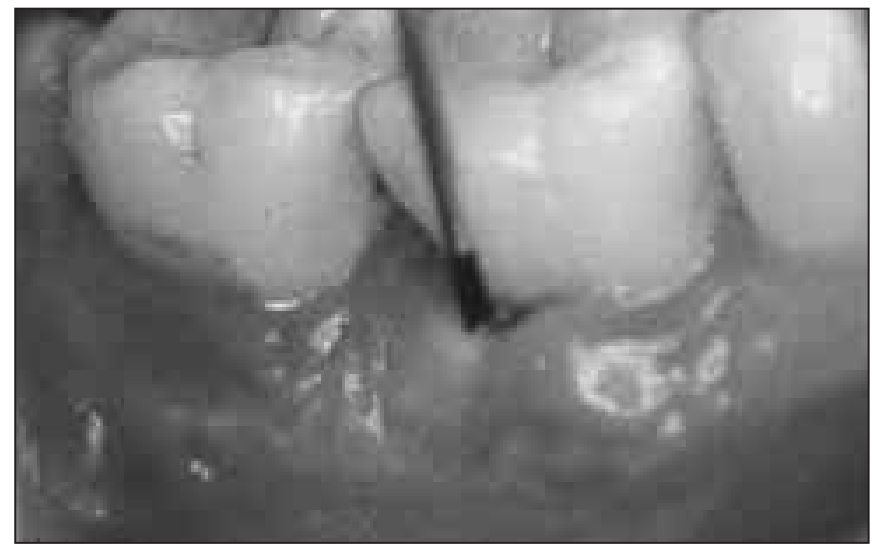

Fig. 10. Drenaje de un abceso periodontal. Drainage of a periodontal absces.

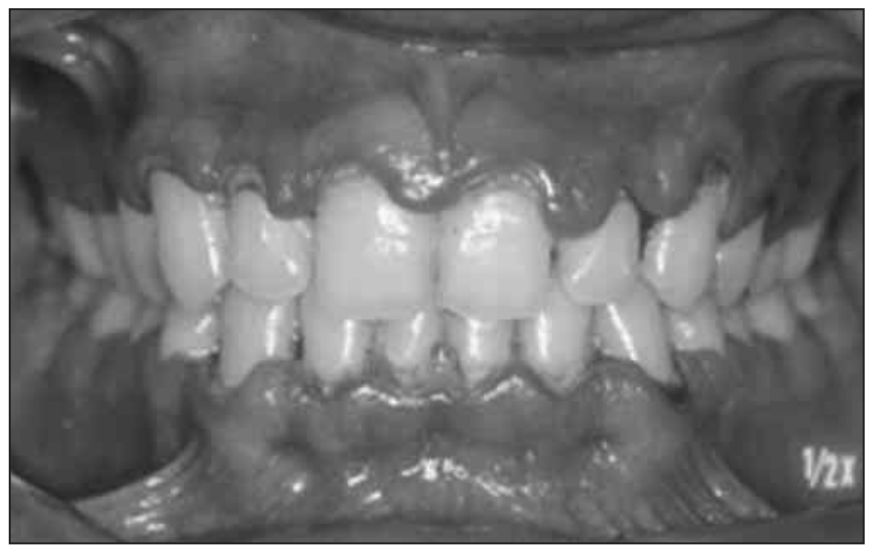

Fig. 11. Enfermedad periodontal necrotizante. Necrositing periodontal disease.

una manifestación clínica en pacientes con periodontitis moderada o severa. Se caracterizan por inflamación, supuración, enrojecimiento, extrusión del diente implicado y diente sensible a la percusión. A veces aparece una ligera elevación de la temperatura (21) (Fig. 10 y 11). Los abscesos pueden ser clasificados en:

-Absceso gingival. Lesión localizada, dolorosa, rápidamente expansiva que afecta al margen gingival o a la papila interdental. Suele ser una respuesta inflamatoria aguda de la encía a un cuerpo extraño introducido en la encía.

-Absceso periodontal. Acumulación localizada de pus en la pared gingival de una bolsa periodontal que origina la destrucción de la inserción de fibras colágenas y la pérdida del hueso alveolar adyacente. Suele estar asociado a la existencia de bolsas periodontales tortuosas, furcas afectadas o defectos infraóseos.

-Absceso pericoronal. Acumulación localizada de pus sobre el tejido gingival que rodea la corona de un diente que no ha erupcionado completamente, generalmente en la zona del tercer molar inferior. El tejido gingival aparece rojo e inflamado y los pacientes pueden encontrar dificultades para tragar.

\section{Lesiones periodontales-endodónticas}

Las infecciones de origen periodontal o endodóntico pueden cur-sar con un incremento en la profundidad de sondaje de los dien-tes adyacentes, inflamación, sangrado al sondaje, supuración, formación de fístula, sensibilidad a la percusión, incremento en la movilidad del diente, pérdidas óseas angulares y dolor. Estos signos y síntomas suelen aparecer en periodontitis asociadas a placa que comienzan en el margen gingival y progresan apical-mente. Sin embargo, también pueden estar causadas por infecciones endodónticas que alcanzan al ligamento periodontal a través del foramen apical o a través de los canales laterales o accesorios y avanzan coronalmente (22).

\section{Condiciones y deformidades desarrolladas o adquiridas}

Existe una serie de factores relacionados con el diente que pueden predisponer a la aparición de enfermedades periodontales. De este modo, aunque la etiología de las enfermedades periodontales sea bacteriana, todos aquellos factores que favorezcan la acumulación bacteriana o permitan el ingreso de bacterias en el periodonto deben ser considerados (23). Deformaciones mucogingivales, alteraciones de la morfología, dimensiones e interrelaciones entre la encía y la mucosa alveolar. Esta anomalía puede estar asociada con deformaciones del hueso alveolar subyacente (24). Trauma oclusal: daño resultado de cambios tisulares en el aparato de inserción como resultado de una fuerza oclusal. Puede ser primario, cuando las fuerzas oclusales excesivas inciden sobre un diente con un soporte normal; o secundario, cuando el daño resulta de la aplicación de fuerzas oclusales excesivas o normales sobre diente/s con un periodonto reducido (25).

\section{CONCLUSIÓN}

La revisión expuesta permite tener una idea global de los diferentes cuadros clínicos de las enfermedades periodontales. Se ha visto como en todos ellos las bacterias juegan un papel importante en el inicio y posterior desarrollo de las mismas. Por lo que a la hora de tratarlas, sabiendo de antemano que el raspado y alisado radicular por sí solo no siempre consigue eliminar los patógenos periodontales, será necesario el empleo de antimicrobianos de manera coadyuvante (26-29). La selección de los antimicrobianos se basa en los criterios microbiológicos de la enfermedad (espectro de acción) así como en las características farmacocinéticas del agente concreto seleccionado, evitando en cualquier caso los efectos adversos del mismo (30,31). El empleo de antimicrobianos de forma local permite conseguir niveles de fármaco que 


\section{AVANCES}

no podrían ser alcanzados de forma sistémica, o incluso la utilización de agentes demasiados tóxicos para ser empleados de forma sistémica (32). Sin embargo, por otro lado, los antibióticos sistémicos ejercen su efecto en todas las zonas de la cavidad oral, no estando sólo limitados a su zona de aplicación (1,32-34). Por ello, se recomienda la utilización sistémica de amoxicilina, amoxicilina-ácido clavulánico y metronidazol como primera opción para el tratamiento de las enfermedades periodontales agresivas. En caso de pacientes alérgicos a amoxicilina o metronidazol, se sugiere el empleo de clindamicina, azitromicina o claritromicina (35).

\section{CORRESPONDENCIA}

Dr. D. Antoni Bascones Martínez

Dpto. Estomatología III Facultad de Odontología Universidad Complutense de Madrid

Ciudad Universitaria

28040 Madrid 